\title{
Correlation between Magnetic Resonance Cerebrospinal Fluid Flowmetry with the Clinical Outcome of Craniocervical Decompression Surgery for Chiari Type One Patients
}

\author{
MOHAMED A. THABIT, M.D.*; EHAB ABDELHALEM ALI, M.D.*; \\ WESSAM ABDELRAHMAN ELZAYAT, M.D.** and OMAR ABDELALEEM RAGAB, M.D.*** \\ The Departments of Neurosurgery*, Radiology**, Faculty of Medicine, Cairo University, Cairo and \\ The Department of Neurosurgery, Faculty of Medicine, Beni-Suef University, Beni-Suef***, Egypt
}

\begin{abstract}
Background: Patients having chiari 1 have caudal displacement of the cerebellar tonsils more than $5 \mathrm{~mm}$ below the foramen magnum. The brainstem is in a normal position. They may or may not have a syrinx. The 5-mm "rule" concerning the definition of the pathologic extent of the caudal migration of the tonsils is arbitary. Patients with a Chiari1 Malformation may present with a variety of symptoms and signs ranging from headache to severe myelopathy and brainstem compromise. Chiari malformation type I develops as the skull and brain are growing. As a result, signs and symptoms may not occur until late childhood or adulthood Structural MRI is the main imaging diagnostic tool, often accompanied by cine Phase-Contrast (PC) MRI of the Cerebrospinal Fluid (CSF) flow.
\end{abstract}

Aim of Study: To establish a correlation between clinical and MRI flowmetry following craniocervical decompression surgery.

Patients and Methods: Twenty patients with symptomatic chiari 1 malformation had MRI flowmetric studies prior to surgery and six months post-operatively and the flowmetry results are assigned to each patient in comparison with clinical improvement.

Results: Sixteen patients had clinical and radiological improvement,one patient clini-cally stayed the same though radiologically improved and 3 patients deterio-rated clinically with radiological evidence of CSF flow obstruction needed resurgery.

Conclusion: CSF flowmetry is a good diagnostic and prognostic tool in chiari type 1 malformation.

Key Words: Chiari type 1-Cine MRI-CSF flowmetryCraniocervical decompression.

Correspondence to: Dr. Mohamed A. Thabit, The Department of Neurosurgery, Cairo University, Cairo, Egypt

\section{Introduction}

CHIARI malformations are a group of complex congenital malformations with variable degrees of hind brain involvement $[\mathbf{4 , 8 , 9 ]}$ there are five types where type one includes a group of patients having tonsillar herniation more than half centimeter caudal to the foramen magnum $[4,9,12]$. The brain stem is not displaced but a spinal syrinx is commonly present, while hydrocephalus is not commonly present. There may be some associated anomalies that may be associated with the condition like Klippel-feil syndrome, odontoid retroflex-ion, neurofibromatasis and many others. These patients may suffer from wide range of symptoms and signs like headache, radicular pain, para/hyposthesia, motor deficit, dysphagia and dysarthria $[\mathbf{9 , 1 3 , 1 4}$, 16,20]. Cerebellar symptoms, brain stem symptoms, and spinal cord affection is also common. Diagnosis of the condition is based on both clinical suspiscion and several diagnostic studies namely C.T. scans and MRI $[14,16,20]$. The main features in MRI is tonsillar herniation, crowded foramen magnum with lack of CSF surrounding the tonsils on T2 weighted images [1-3,5]. MR is also sensitive for detecting syrinx formation and further MRI spinal imaging can detect its extension [5-7,10]. A good diagnostic tool for detecting CSF flow abnormalities around foramen magnum is CSF MR flow metric studies namely CINE MRI which is not only used to solidify the diagnosis it may be used postoperatively to judge the adequacy of the decompression and the prognosis for relapses $[\mathbf{7 , 1 0}$,

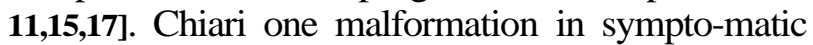
individuals needs surgical interference mainly be craniocervical de-compression surgery and hydrocephalus is also addressed first if present $[4,8,20]$. 
Syrinx usually resolves within the first six months following surgery $[\mathbf{8 , 2 0 ]}$. While most patients improve there is an incidence of $10 \%$ or less may worsen with time and recurrence of syrinx needing resurgery $[\mathbf{1 4 , 1 6 , 2 0 ]}$. In Chiari malformation craniocervical decompression surgery is thought to reestablish normal CSF circulation at the cranio-cervical junction $[\mathbf{8 , 9 , 1 6}$. Neuroimaging techniques improve our anatomical understanding of such patients and may help us to determine the type and required extent of cranio-cervical decompression [11,15,18,19].

\section{Patients and Methods}

Twenty patients were included in the study with symptomatic Chiari type 1 . Recurrent cases were not included. All patients were assessed by thorough history and clinical examination, pre-operative MRI brain and cervical spine along with MR CSF flowmetry. At the post-operative period patients were assessed clinically at three months interval and had MR brain and CSF flowmetry at six month and one year intervals. All patients had craniocervical decompression surgery and are followed-up clinically immediate post-operative and every three months.

The MR studies were performed at Al-Kasr AlAiny Hospital using Philips Achieva 1.5 Tesla SE. No pre-examination special precautions were taken. Most of the patients needed short term sedation. Circular polarized head-array coil was used.

\section{The examination protocol:}

The examination started by:

A- Conventional MR sequences: Axial and sagittal T2WIs for the whole brain $(\mathrm{TR} / \mathrm{TE}=1500 / 100$ $\mathrm{ms}$, slice thickness $=6 \mathrm{~mm}$, number of acquisition $=2$ and matrix $256 \times 256$ ).

Sagittal T2WIs for the foramen of magnum ( $\mathrm{TR} / \mathrm{TE}=1500 / 100 \mathrm{~ms}$, slice thickness $=4 \mathrm{~mm}$, number of acquisition $=2$ and matrix $256 \times 256$ ).

$B$ - CSF flow sequences: Phase-Contrast MR imaging (PCMR): In axial and sagittal planes across the foramen of magnum. Two-dimensional Fast Low Angle Shot (FLASH) se-quence images ( $\mathrm{TR} / \mathrm{TE}=20 / 9 \mathrm{~ms}$, flip angle $=20$, slice thickness $=4 \mathrm{~mm}$, number of acquisitions 2 , Field of View ( FOV) $=180 \mathrm{~mm}$; matrix $256 \times 256$ and encoding velocity $8-10 \mathrm{~cm} / \mathrm{s})$. The phase contrast images were synchronized to the electrocardiogram in 16 phases. The flow encoding was directed caudo-cranial.

\section{MR interpretation:}

The CSF flow was analyzed in qualitative and quantitative ways. The qualitative analysis was assessed using sagittal phase contrast images and displayed in gray scaled cine images. Flipping of CSF signal from low to high and vice versa indicated bidirectional flow. While the quantitative analysis was assessed using axial phase contrast images that planed just inferior to the tip of the cerebellar tonsils. The Region of Interest (ROI) was placed within the anterior and posterior subarachnoid space surrounding the spinal cord. Measurement of the CSF flow dynamics is demonstrated by line graph. The $\mathrm{Y}$ axis referred to the velocity of CSF flow above and below the baseline according to direction of flow. The $\mathrm{X}$ axis referred to time fraction of cardiac cycle.

Positive findings of CSF flow across the tonsillar herniation of Chiari I mal-formation included: (I) Loss of bidirectional CSF flow across the foramen of magnum, (II) Synchronous bidirectional CSF flow, (III) Sluggish or impeded CSF flow at the anterior or posterior subarachnoid space, (IV) Jet flow across the foramen magnum.

\section{Results}

The study was conducted in Cairo University Hospital from May 2017 till November 2019 included 13 males and 7 females, mean age was 13 years, the main presentation was sensory affection in the form of numbness and hyposthenia (jacket sensory loss), motor deficit was found only in three patients mainly hand weakness, cerebellar manifestations and ataxia were found in nine patients, cranial nerve deficit (mainly bulbar palsy) was found in 3 patients and all patients had cervical syrinx in MRI. Pre-operative CSF MR flowmetry showed loss of bidirectional CSF flow across the foramen of magnum, synchronous bidirectional CSF flow, sluggish or impeded CSF flow at the anterior or posterior subarachnoid space and jet flow across the foramen magnum. There was significant increase in velocity post-operatively in follow-up MR CSF flowmetry. Clinical improvement occurred in 16 patients with no recurrence of symptoms, recurrence of symptoms occurred in three patients with post-operative MR CSF flowmetry showing impeded flow across foramen magnum and a redo was done.one patient retained the same clinical course with radiological improvement. Tow patients had hydrocephalus postoperative and needed shunt surgery. Follow-up period ranged from 12 to 23 months average of 15 months. 


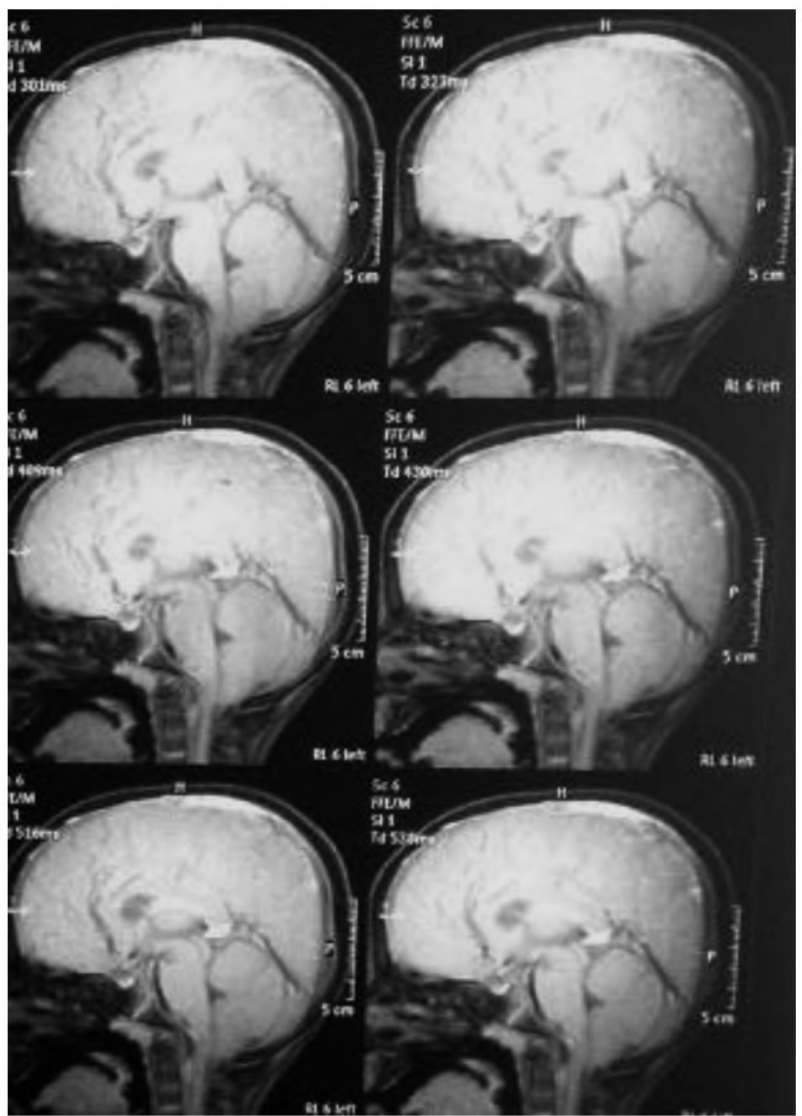

Fig. (1): Pre-operative MRI of a five years old boy having tonsillar herniation.

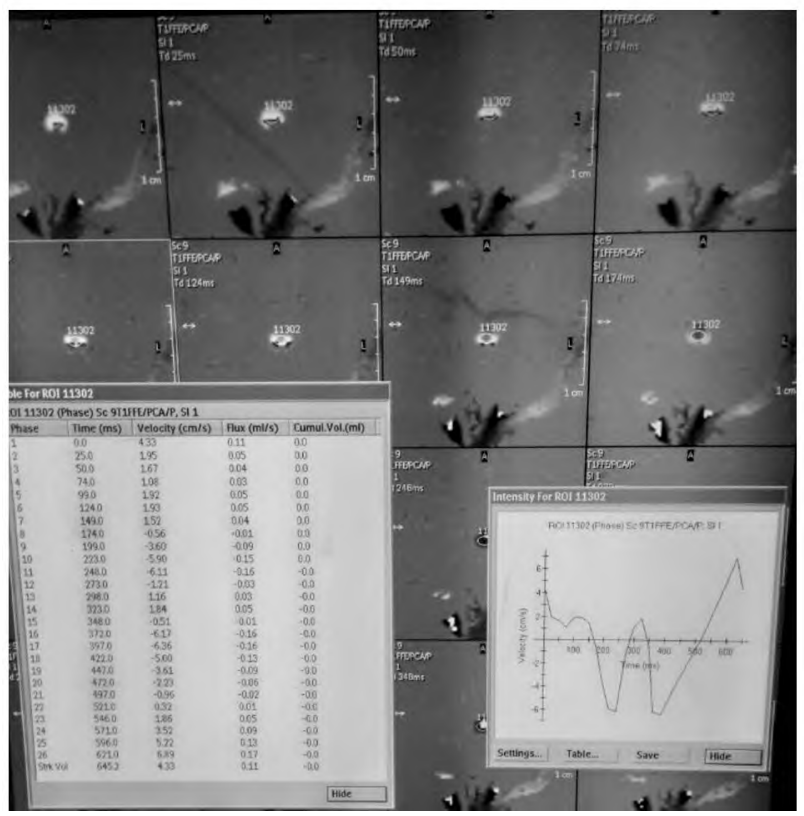

Fig. (3): MR CSF flowmetry of the same patient showing the velocities across foramen magnum which is markedly reduced.

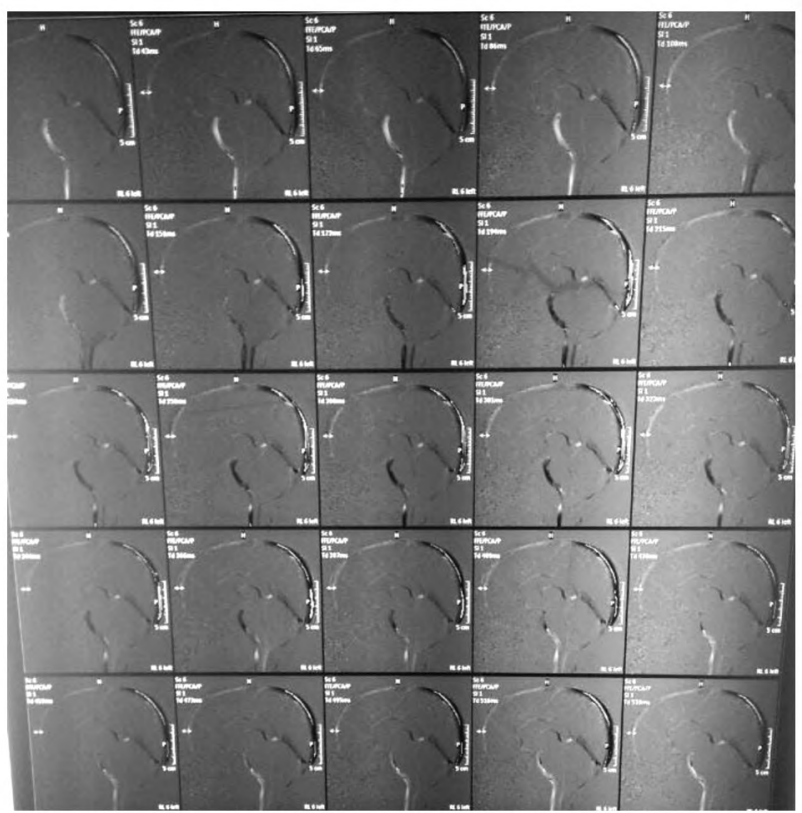

Fig. (2): Pre-operative CSF flowmetry of the same patient showing impeded flow at the anterior.

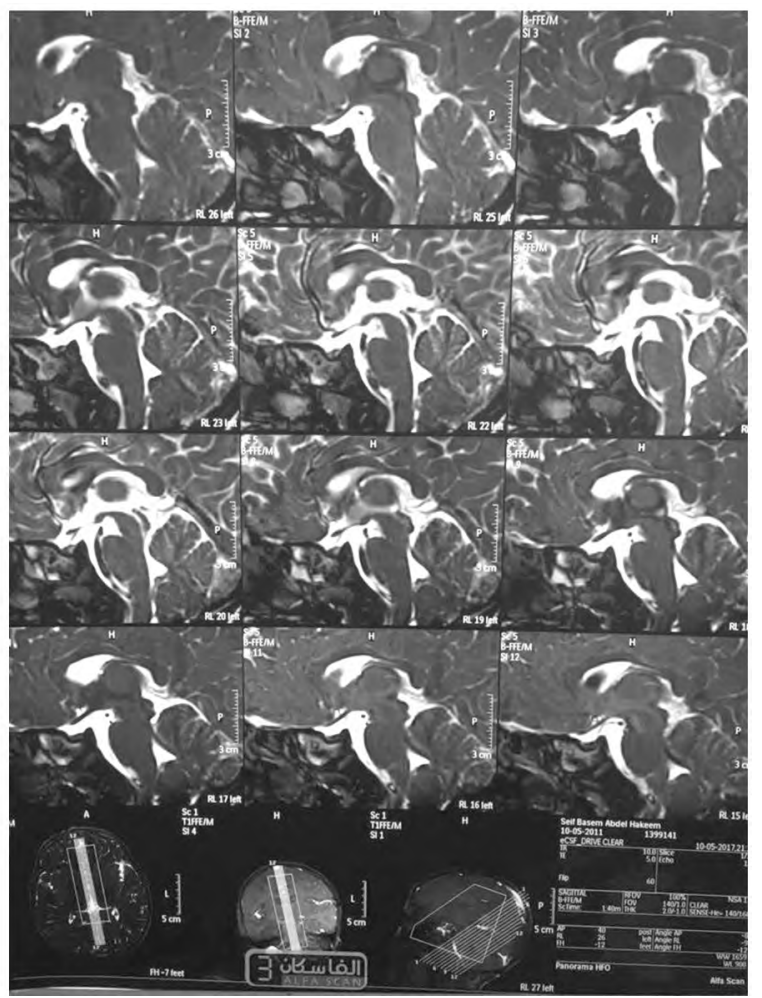

Fig. (4): Post-operative MRI after 6 months of the same patient showing good decompression in addition the presence of good flowmetric flow (no signal void) at the prepontine and anterior cervical spaces. 


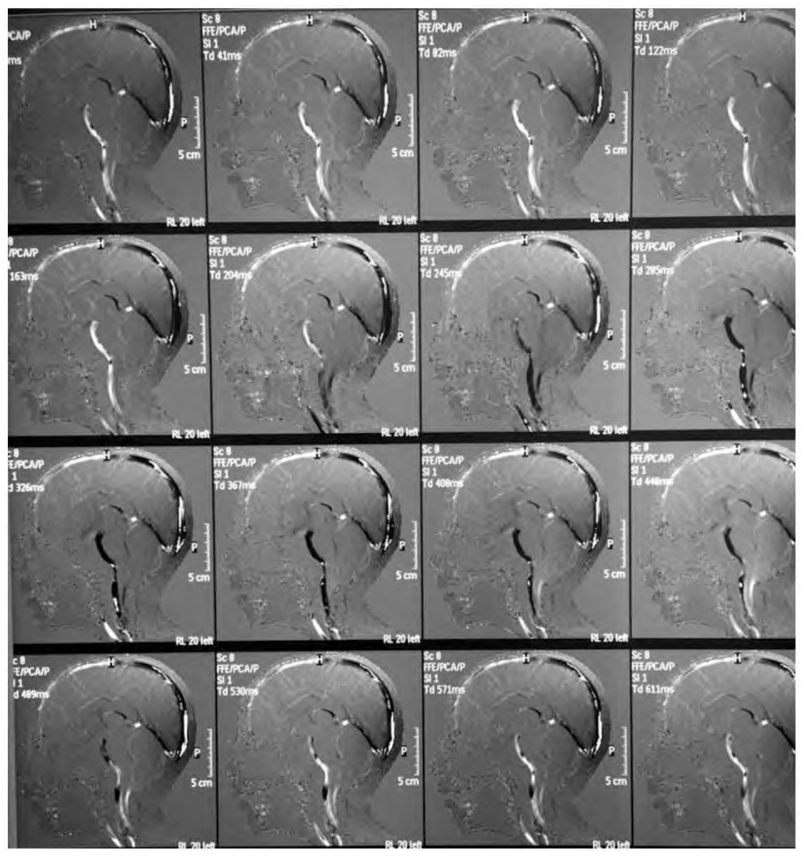

Fig. (5): Post-operative MRI after 6 months of the same patient showing good decompression in addition the presence of good flowmetric flow (no signal void) at the prepontine and anterior cervical spaces.

Table (1): CSF flow velocities using cine MRI pre and postoperatively in relation to the outcome.

\begin{tabular}{lccl}
\hline & $\begin{array}{c}\text { Pre-operative } \\
\text { velocities }\end{array}$ & $\begin{array}{c}\text { Post-operative } \\
\text { velocities }\end{array}$ & Out-come \\
\hline 1 & 4.33 & 5.78 & Improved \\
2 & 1.95 & 7.23 & Improved \\
3 & 1.67 & 6.54 & Improved \\
4 & 1.08 & 4.74 & Relapses \\
5 & 1.92 & 1.23 & Improved \\
6 & 1.93 & 2.17 & Improved \\
7 & 1.52 & 5.32 & Improved \\
8 & 0.56 & 3.17 & Improved \\
9 & 3.6 & 0.56 & Improved \\
10 & 5.9 & 4.35 & Improved \\
11 & 6.11 & 5.11 & Improved \\
12 & 1.21 & 4.97 & Improved \\
13 & 1.16 & 5.78 & Improved \\
14 & 1.84 & 5.14 & Relapses \\
15 & 0.51 & 1.19 & Relapses \\
16 & 6.17 & 7.33 & Improved \\
17 & 6.36 & 7.42 & Improved \\
18 & 5 & 6.31 & Improved \\
19 & 3.61 & 4.72 & Same \\
20 & 2.23 & 4.13 & Improved \\
\hline & & & \\
\hline & & &
\end{tabular}

The above velocities are in mean values were pre-operative velocities have \pm 0.5 .

And the post-operative have \pm 0.6 deviations.

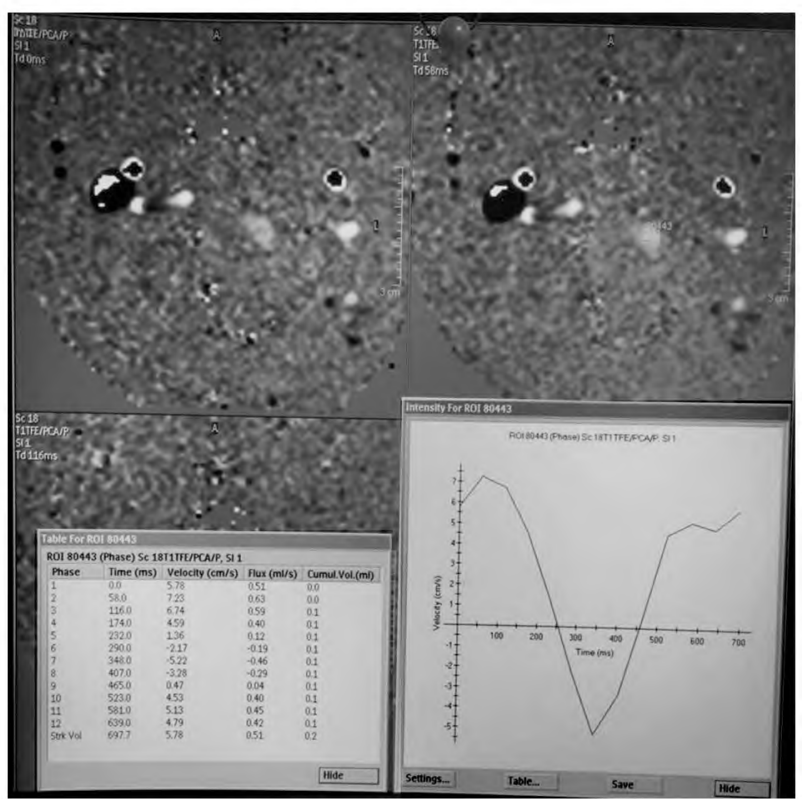

Fig. (6): Post-operative measures for the flow velocities of the same patient showed marked increase at CSF velocities.

\section{Discussion}

This study demonstrated that MR CSF flowmetry can be used to measure CSF flow velocity and evaluate whether craniocervical decompression has restored cervical CSF flow in Chiari malformation. Our results indicate that in chair type 1 the posterior cervical flow velocity is very low, increases after surgery and is not related to the progression of the syrinx. In patients who have only cerebellar descent with no other anatomical abnormalities, three MR discoveries after surgery have predictive value: (1) Increase of the sum of anterior and posterior cervical spaces velocities by more than $25 \%$, compared to preoperatively,

(2) Elimination of pulsatile flow in the syrinx and

(3) Higher velocity in the anterior cervical than the prepontine cisterns, by at least $30 \%$, indicated no impedance at caudal CSF flow and predicted clinical improvement. This also coincided with clinical improvement of the pre-operative symptoms. The progression of the syrinx was not an important criterion predicting improvement and its persistence was not significant in any way regarding the symptomatology. On the other hand, the change of pulsa-tile impulse across the syrinx is an important prognostic factor for the clini-cal outcome and it usually precedes the disappearance of the syrinx. 
CSF flow across foramen magnum in chiari 1 patients plays a role in the pathophysiology of the disease, the flow velocities is markedly decreased compared to the normal persons. Increased CSF flow velocities occurred after surgery the main increase is at the anterior cervical space which reaches the normal values and sometimes may show an increased flow above the normal value, it also is higher than the prepontine cistern flow velocity. On the other hand, the posterior cervical space shows increase flow but not that significantly increased actually it may not reach the normal values but the summation of both the anterior and posterior cervical spaces usually exceeds the prepontine space. Sakamoto et al., [20] used cardiacgated phase contrast cine MRI to assess patients with chiari type 1 pre and post-operatively and had similar results. Hoffmann et al., [11] and Haughton et al., [9] obtained numerical values similar to our study also which solidifies the concept that the better the post-operative flow velocities the better the outcome.

\section{References}

1- ADRIAN KORBECKI, ANNA ZIMNY, PRZEMYSÓAW PODGÓRSKI, MAREK S ASIADEK and JOANNA BLADOWSKA: Imaging of cerebrospinal fluid flow: Fundamentals, techniques, and clinical applications of phase-contrast magnetic resonance imaging; Pol. J. Radiol., 84: e240-e250, 2019.

2- BUNCK A.C., KROEGER J.R., JUETTNER A., et al.: Magnetic resonance 4D flow analysis of cerebrospinal fluid dynamics in Chiari I malformation with and without syringomyelia. Eur. Radiol., 22: 1860-70, 2012.

3- BHADELIA R.A., BOGDAN A.R., WOLPERT S.M., LEV S., APPIGNANI B.A. and HEILMAN C.B.: Cerebrospinal fluid flow waveforms: Analysis in patients with Chiari I malformation by means of gated phase-contrast MR imaging velocity measurements. Radiology, 196: 195-202, 1995

4- CHAVEZ A., ROGUSKI, M. KILLEEN, A. HEILMAN, C. and HWANG S.: Comparison of operative and nonoperative outcomes based on surgical selection criteria for patients with Chiari I malformations. J. Clin. Neuroscience., 21 (12): 2201-6, 2014.

5- CHAVEZ A., ROGUSKI, M. KILLEEN, A. HEILMAN, C. and HWANG S.: Comparison of operative and nonoperative outcomes based on surgical selection criteria for patients with Chiari I malformations. J. Clin. Neuroscience., 21 (12): 2201-6, 2014.

6- ENZMANN D.R. and PELC N.J.: Normal flow patterns of intracranial and spinal cerebrospinal fluid defined with phase-contrast cine MR imaging. Radiology, 178: 46774, 1991.

7- FEINBERG D.A.: Modern concepts of brain motion and cerebrospinal fluid flow. Radiology, 185: 630-2, 1992.

8- GREENBERG J., LADNER T., OLSEN M., et al.: Complications and Resource Use Associated With Surgery for
Chiari Malformation Type 1 in Adults. Neurosurgery, 77 (2): 261-8, 2015.

9- HAUGHTON V.M., KOROSEC F.R., MEDOW J.E., DOLAR M.T. and ISKANDAR B.J.: Peak systolic and diastolic CSF velocity in the foramen magnum in adult patients with Chiari I malformations and in normal control participants. Am. J. Neuroradiol., 24: 165-6, 2003.

10- JIA LONG, HAI LIN, GAN CAO, MENG-ZHU WANG, XIAN-JIAN HUANG, JUN XIA and ZHONGHUA SUN: Relationship between intracranial pressure and phasecontrast cine MRI-derived measures of cerebrospinal fluid parameters in communicating hydrocephalus. Quant Imaging Med. Surg., 9 (8): 1413-20, 2019.

11- KILLEEN A., ROGUSKI M., CHAVEZ A., HEILMAN C. and HWANG S.: Non-operative outcomes in Chiari I malformation patients. J. Clin. Neuroscience, 22 (1): 133$8,2015$.

12- KYOSHIMA K., KUROYANAGI T., OYA F., KAMIJO Y., EL-NOAMANY H. and KOBAYASHI S.: Syringomyelia without hindbrain herniation: D.E. Sakas et al. tight cisterna magna. Report of four cases and a review of the literature. J. Neurosurg., 96 (Suppl) 2: 239-49, 2002.

13- LAKSHMI A.S.: Position of Cerebellar Tonsils in Reference to Fora-men Magnum: An MRI Study. Journal of Evolution of Medical and Dental Sciences, 4 (94): 159704, 2015.

14- LEU R.: Sleep-Related Breathing Disorders and the Chiari 1 Malformation. Chest, 148 (5): 1346-52, 2015.

15- MASSIMI L., PEPA G., TAMBURRINI G. and Di ROCCO C.: Sudden onset of Chiari malformation Type I in previously asymptomatic patients. J. Neurosurg. Pdiatr. ,8 (5): 438-42, 2011.

16- OLDfiELD E.H., MURAZKO K., SHAWKER T.H. and PATRONAS N.J.: Pathophysiology of syringomyelia associated with Chiari I malformation of the cerebellar tonsils. J. Neurosurg., 80: 3-15, 1994.

17- PATIENCE N. BUUMBA, MOONO SILITONGO, HILDA ZULU, DAILESI NDHLOVU, BOYD MUDENDA and KRIKOR ERZINGASTIAN: Position of the Cerebellar Tonsils in Relation to the Anteroposterior Diameter of the Foramen Magnum in Individuals of Different age groups: The Zambian Experience. Journal of Preventive and Rehabilitative Medicine, 1 (1): 67-73, 2016.

18- PUJOL J., ROIG C., CAPDEVILA A., POU A., MARTIVILALTA J.L., KULISEVSKY J., ESCARTIN A. and ZANNOLI G.: Motion of the cerebellar tonsils in Chiari type I malformation studied by cine phase-contrast MRI. Neurology, 45: 1746-53, 1995.

19- RAMOS A., et al.: Cerebellar Anatomy as Applied to Cerebellar Microsurgical Resections. Arq. Neuropsiquiatr., 70 (6): 441-6, 2012.

20- SAKAMOTO H., NISHIKAWA M., HAKUBA A., YASUI T., KITANO S., NAKANISHI N. and INOUE Y.: Expansive suboccipital cranioplasty for the treatment of syringomyelia associated with Chiari malformation. Acta Neurochir (Wien), 141: 949-60, 1999. 


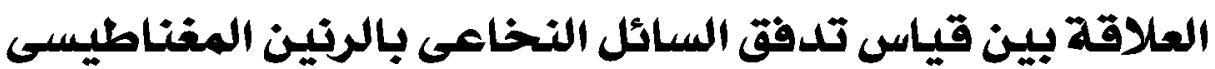

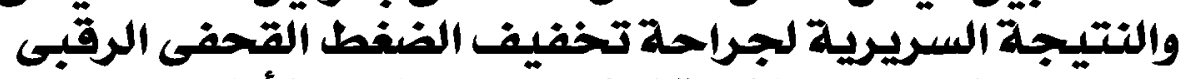

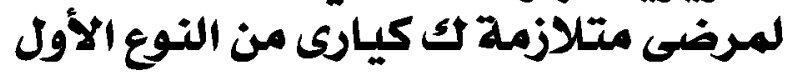

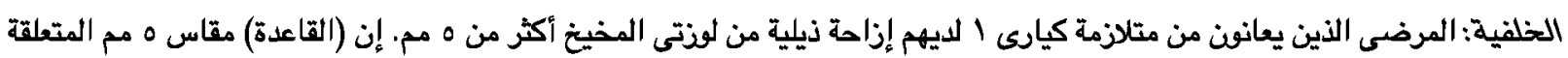

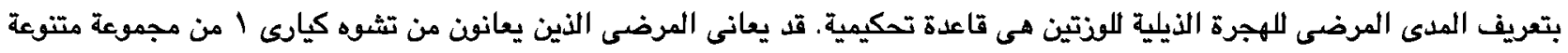

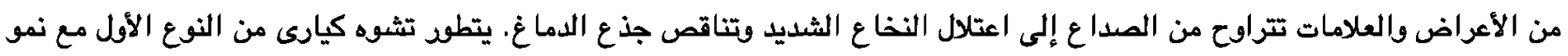

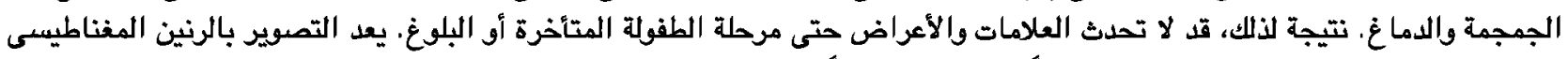

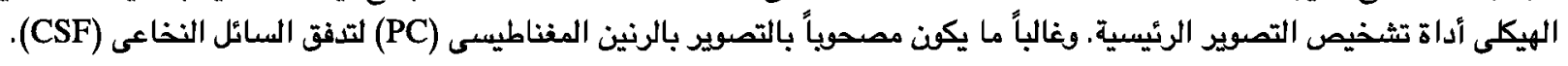
هدف الدراسة: لتأسيس علاقة بين التقيق السر برى ومقاييس التصوير بالرنين المفناطيسى بعد جراحة تخفيف الضغط القدئ القدفى الرقبى:

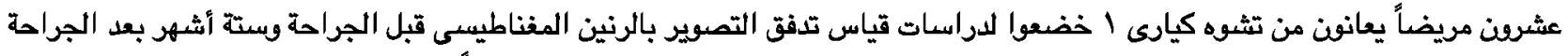

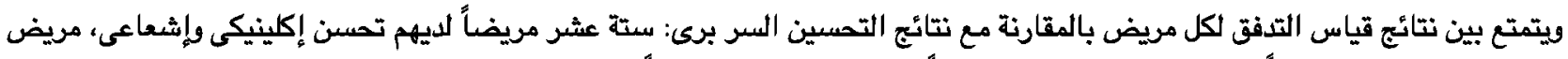

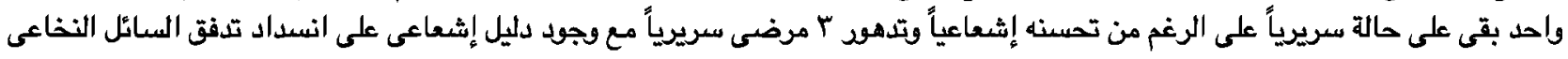
بحاجة إلى إعادة الجراحة. الخلاصة: قياس تدفق السائل الدماغى النخاعى هو أداة تثخيصية جيدة فى تشوه كيارى من النوع الأول. 